\title{
Motivation and learning in mice after goldthioglucose-induced hypothalamic lesions 1,2
}

JERI A. SECHZER, STEVEN G. TURNER AND ROBERT A. LIEBELT

BAYLOR UNIVERSITY COLLEGE OF MEDICINE
Shock-avoidance training was given to normal mice and to mice with goldthioglucose-induced lesions in the ventromedial region of the hypothalamus. The lesioned mice learned faster than the control mice. Lesions in the ventromedial region of the hypothalamus may alter the emotionality of an animal and thus its motivation during learning.

The role of the hypothalamus in the regulation of food intake has been well documented in the literature. Bilateral electrolytic lesions in the ventromedial region of the hypothalamus in a rat will induce a hyperphagia and subsequent obesity. In contrast to this phenomenon, lesions in the lateral area of the hypothalamus result in aphagia and subsequent starvation.

Much effort has been expended in the elucidation of how these hypothalamic centers regulate food intake. The first experiment of Hetherington \& Ranson (1939) 25 years ago and that of Anand \& Brobeck (1951) 15 years ago resulted in the concept of dual centers regulating feeding and hunger. Stellar (1954), Teitelbaum (1955) and others have refined and clarified this concept. In addition, they have shown the importance of motivational variables that interact with these hypothalamic centers and thus further influence feeding and hunger.

Recent observation of the behavior of animals after electrolytic ventromedial hypothalamic lesions have suggested that this center may be concerned with functions other than feeding. The experiments reported here investigate the role of the ventromedial hypothalamic region in motivation and learning in the mouse under shock-avoidance conditions.

A single injection of goldthioglucose has been shown to induce bilateral lesions in the ventromedial region of the hypothalamus in mice. These goldthioglucoseinduced lesions in mice result in hyperphagia and obesity similar to that seen in rats with electrolytic lesions in this same area (Liebelt \& Perry, 1957). The experimental mice used in this study were treated with goldthioglucose in an attempt to make discrete lesions in the ventromedial region of the hypothalamus. Method

The Ss were 39 adult male mice of three different strains (A/Ki, CBA/Ki, CBA/JAX). Twenty of the mice represented our control group; the remaining 19, our experimental group. Prior to any training procedure all experimental mice received intraperitoneal injections of goldthioglucose (Solganol $\mathrm{B})^{3}$ according to weight and strain. These animals showed a rapid increase in food intake reflected by daily weight gains.
The majority of mice started training approximately 22 days after goldthioglucose adminstration.

\section{Procedure}

Experimental and control mice were trained in an electrified Y-maze with a metal grid floor similar to that previously described by Flexner, Flexner, \& Stellar (1963). An opaque barrier divided the stem of the $Y$ into a start box and an alley. In order to avoid shock the mouse had to move from the start box, down the alley and into the correct arm of the maze within $5 \mathrm{sec}$. Shock was given if after $5 \mathrm{sec}$. the mouse had not entered the correct arm of the maze. For half of the animals the right arm was correct and for the remainder the left arm was correct. Each animal was trained at its own shock threshold level. These thresholds were determined individually for each mouse using a modified method of Evans (1961). Twenty training trials a day were given until a criterion of $80 \%$ or more correct responses was reached and maintained for three consecutive days. At the termination of the experiment, the mice were killed, their brains removed from the cranium and prepared for microscopic examination.

Results

All experimental mice and all control mice successfully learned the shock-avoidance problem. Figure 1 compares the training trials of two goldthioglucoselesioned mice with those of two normal control mice. The goldthioglucose-lesioned mice each required only 40 trials to reach the criterion of learning whereas the two normal mice required 120 and 160 trials respectively to reach the same criterion. Figure 2 shows the results of all experimental and control mice used in

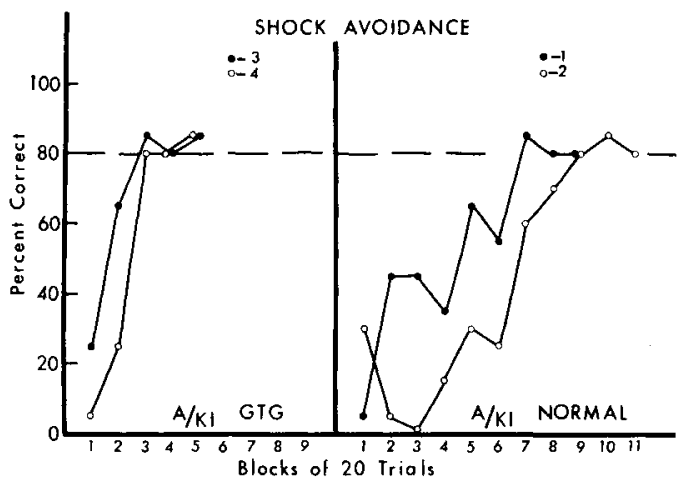

Fig. 1. Learning curves of two goldthioglucose (GTG) lesioned mice compared with learning curves of two normal mice. Each lesioned mouse took 40 trials to reach criterion. Normal mice took 120 and 160 trials respectively. 


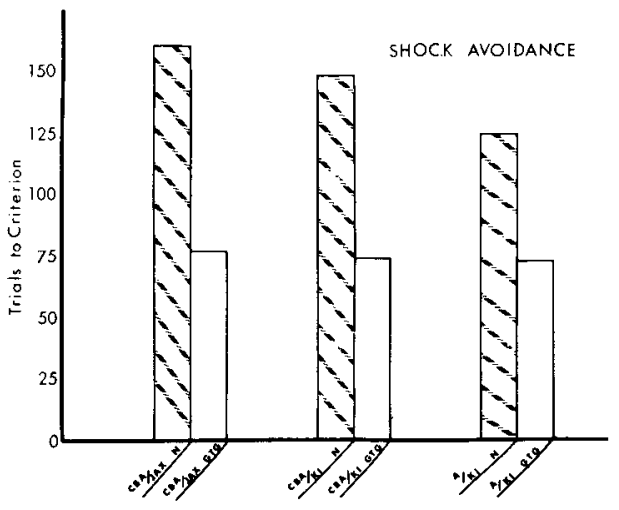

Fig. 2. Comparison of trials to the criterion of learning required by goldthioglucose (GTG) lesioned mice and normal mice according to strain. Regardless of strain, GTG lesioned mice learn more rapidly than normal mice.

this study. Comparison of lesioned to normal mice is presented according to strain. The results shown here clearly indicate that regardless of strain, the goldthioglucose-lesioned mice reach criterion in approximately half the number of trials as their controls. Discussion

One possible explanation of these present findings requires the assumption of a change in the emotionality of the animal as a result of the ventromedial lesions. Our observations of the mice throughout the experiment support this hypothesis. The firstobservation was a marked increase in sensitivity to shock (pain) in the goldthioglucose-lesioned mice. Shock thresholds were found to be consistently lower than those of the control mice. Although each mouse was trained at its own shock threshold, Iatencies of response were shorter in the lesioned mice. In addition, the normal mice showed more "freezing" behavior both during shock and during the 5 sec. interval. "Freezing" was usually accompanjed by urination and defecation. On the other hand, the lesioned mice tended to escape from shock quite readily and consequently showed much less "freezing" with a marked decrease in urination and defecation.

The results and observations presented here strongly suggest that ventromedial hypothalamic lesions alter the emotionality of the animal, affecting its motivation during learning under noxious conditions. Elimination of "freezing"' and the resultant shorter latencies in the goldthioglucose-lesioned mouse appeared to help the animal during learning. In contrast, the normal mouse "froze" almost immediately and appeared immobilized in the presence of shock or a signal of oncoming shock. Consequently, this animal may have taken longer to learn because it had to first overcome this emotional response to the noxious situation.

It must be emphasized that although our results appear to be significant no generalization can be made from the mouse to other species such as the rat or cat. We also cannot state at this time whether our results are independent of goldthioglucose and whether similar results would be obtained after electrolytic lesions in this area of the hypothalamus.

Finally, further studies are necessary with foodreward training to determine whether this phenomenon is a general one or is related only to negative reinforcement situations.

\section{References}

Anand, B. K., \& Brobeck, J. R. Hypothalamic control of food intake. Yale J. Biol. Med., 1954, 24, 123-140.

Evans, W. O. A new technique for the investigation of some analgesic drugs on reflexive behavior in the rat. Psycholpharmacol. $1961,2,318$.

Flexner, J. B., Flexner, L. B., \& Stellar, E. Memory in mice as affected by intracerebral puromycin. Science, 1963, 141, 57-59.

Hetherington, A. W., \& Ranson, S. W. Experimental hypothalamicohypophysial obesity in the rat. Proc. Soc. Exp. Biol., 1939, 41, 465-466.

Liebelt, R. A., \& Perry, J. H. Hypothalamic lesions associated with goldthioglucose-induced obesity. Proc. Soc. Exp. Biol. Med., 1957, 95, 774-777.

Stellar, E. The physiology of motivation. Psychol. Rev., 1954, $61,5-22$

Teitelbaum, P. Sensory control of hyperphagia. J. comp. physiol. Psychol., 1955, 48, 156-163.

\section{Notes}

1. Research supported by U.S.P.H.S. Grants No. MH-10792-01 and AM- 1230 .

2. A portion of this paper was presented at the American Physiological Society meeting, Los Angeles, California in August, 1965; abstract published in The Phy.siologist 8, 292 (1965).

3. Courtesy of Schering Corp., Bloomfield, N. J. 